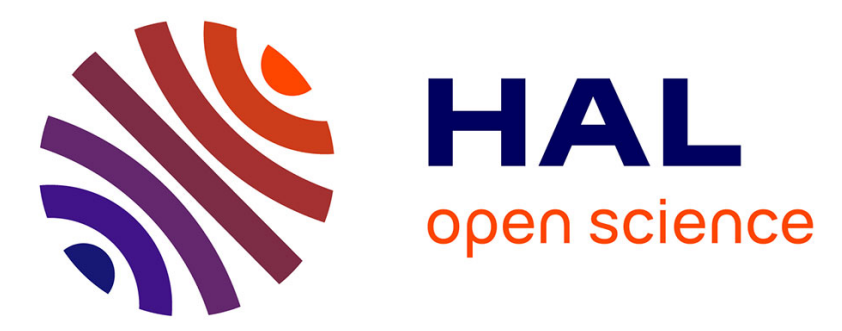

\title{
PHYSICAL BEHAVIOUR MODELLING OF VDMOS DEVICES
}

\author{
J. Paredes, J. Fernandez, F. Berta, S. Hidalgo, J. Rebollo, J. Millan
}

\section{To cite this version:}

J. Paredes, J. Fernandez, F. Berta, S. Hidalgo, J. Rebollo, et al.. PHYSICAL BEHAVIOUR MODELLING OF VDMOS DEVICES. Journal de Physique Colloques, 1988, 49 (C4), pp.C4-625-C4-628. 10.1051/jphyscol:19884130 . jpa-00227867

\section{HAL Id: jpa-00227867 https://hal.science/jpa-00227867}

Submitted on 1 Jan 1988

HAL is a multi-disciplinary open access archive for the deposit and dissemination of scientific research documents, whether they are published or not. The documents may come from teaching and research institutions in France or abroad, or from public or private research centers.
L'archive ouverte pluridisciplinaire HAL, est destinée au dépôt et à la diffusion de documents scientifiques de niveau recherche, publiés ou non, émanant des établissements d'enseignement et de recherche français ou étrangers, des laboratoires publics ou privés. 


\title{
PHYSICAL BEHAVIOUR MODELLING OF VDMOS DEVICES
}

\author{
J. PAREDES, J. FERNANDEZ, F. BERTA, S. HIDAIGO, J. REBOLLO and \\ J. MILLAN
}
Centro Nacional de Microelectrónica, CSIC-UAB, SP-08193 Bellaterra, Barcelona, Spain

\begin{abstract}
Résumé - Nous proposons un modèle analytique pour expliquer le comportenent physique des transistors VDMOS quel que soit le niveau de courant. I'effect de quasi-saturation est pris en compte au travers de la saturation de la vitesse des porteurs à fort champ électrique. Des transistors VDMOS interdigités ont été réalisés et les simulations bidimensionelles effectueés en vue de vêrifier le modèle.
\end{abstract}

Abstract - An analytical model is proposed in order to explain the physical behaviour of VDMOS devices at any DC current level. The quasi-saturation effect is included considering the carrier saturation velocity at high electric fields. Interdigitated VDiros devices have been fabricated and $2 \mathrm{D}$ simulations have been carried out to check the model.

\section{1 - INTRODUCTION}

The vertical DMOS transistor is one of the most usual drivers in power MOS ICs /1/. The linear region of its $I-V$ characteristic has been modelled considering a surface accumulated lajer, the JFET resistance between cells and a bulk epilayer resistance together with the active channel /2/. Moreover, in previous works /3, 4/ the current pinching was responsible for the quasi-saturation (q-s) effect or limitation in the current handling capability typical at high current levels. In contrast, $2 \mathrm{D}$ simulations $/ 5 /$ have not shown current pinching between cells but, contrarily, there is a majority carrier excess in the JFET region, suggesting that q-s effect is due to carrier velocity saturation. The carrier excess was explained by means of a dipole similar to the one formed in a JFET channel under carrier velocity saturation conditions. However, none of the previous models has quantitatively explained these phenomena.

This work is aimed to study the detailed physical behaviour of the VDMOS to avoid the tedious $2 \mathrm{D}$ CAD. Interdigitated VDMOS structures have been fabricated and $2 \mathrm{D}$ simulations /6/ have been carried out in order to check the proposed model.

2 - MODEL

Due to the axial symmetry of the VDHOS structure (see fig 1), current and electric field equations can be simplified to one-dimensional analysis:

$$
\begin{aligned}
& \frac{I}{A(y)}=q \mu\left[n E+\frac{k T}{q} \frac{d n}{d y}\right] \\
& \frac{d}{d y}[A(y) E]=\frac{q}{\varepsilon s} A(y)\left(n_{0}-n\right)
\end{aligned}
$$

where $\mathrm{n}$ is the epilayer doping level and $\mathrm{A}(\mathrm{y})$ is the cross-section area of the current path. Suitable approximations in the different regions of the epitaxy have been taken into account in order to obtain analytical solutions for the electric field distribution and for the majority carrier concentration; as shown in fig. 1, these regions are, namely: a) the surface accumulated layer induced by the gate effect of the MOS structure; b) the JFET region between cells and c) the drift region up to the drain contact.

a) SUPERFICIAL REGION. The limits of this region are the Si-SiO interface and the null electric field point inside the epilayer $\left(y_{b}\right)$, which is a consequence of the device bias; i.e., $V_{G}$ and $V_{D}$ are both positive while the source is grounded, so it must exist a point of 
minimum potential between gate and drain. This region has been splitted into two zones since the electric field changes from very high values at the interface to zero at the other edge. In the first zone under the gate electrode, $S_{1}$, the electric field and the carrier concentration gradient are very sharp so that the drift $\left(\mathrm{J}_{\mathrm{a}}\right)$ and the diffusion ( $\mathrm{J}_{\mathrm{d}}$ ) currents are both much greater than the total current flowing through the VDMOS. Consequently, $n>>n_{0}$ and $\mathrm{J}_{\mathrm{d}}=\mathrm{J}_{\mathrm{a}}$ are appropiate approaches, the solution being:

$E=\left[\frac{1}{\bar{g}_{\mathrm{S}}}+\frac{\mathrm{q}}{2 \mathrm{kT}} \mathrm{y}\right]^{-1}$

$\mathrm{n}=\frac{\varepsilon \mathrm{s}}{2 \mathrm{kT}} \mathrm{E}^{2}$

where $\mathrm{E}_{\mathrm{S}}$ is the surface electric field.

The second zone, $\mathrm{S}_{2}$, lies by the zero electric field point; therefore, $J$ is small and a linear dependence on the electric field has been assumed, $J_{a} \simeq q_{\mu} n_{m} \Sigma, n_{b}$ being the carrier concentration at the $\mathrm{y}_{\mathrm{b}}$ point. Under these conditions the solution is:

$F=A \exp (-a y)-\frac{I}{q \mu n_{b} l}$

$\mathrm{n}=\mathrm{n}_{0}+\mathrm{a} \frac{\varepsilon_{\mathrm{s}}}{\mathrm{q}} \mathrm{A} \exp (-\mathrm{ay})$

where $A$ is an integration constant and $a=\left(n_{b} q^{2} / k T_{E_{S}}\right)^{1 / 2}$. The boundary point of $S_{1}$ and $S_{2}$ zones, the constant $\mathrm{A}$, and $\mathrm{y}_{\mathrm{b}}$ are determined imposing the continuity condition of their solutions.

b) JFET REGION. This region spans from the edge of the former zone up to the point where current is no longer confined by the depletion layer of the body-epitaxy junction. This point is found assuming this junction to be plane in punchthrough mode at the onset of the junction curvature (see fig. 1). Obviuosly, the length of this region depends on the drain voltage but its width remains constant and equals the cell spacing (l). In this sense, and according to this model, there is a modulation of the JFET lenght instead of a modulation of the JFET width as considered in previous works $/ 3,4 /$.

In this region, the carrier concentration is close to $n_{0}$ and consequently $J$ is negligible. An accurate solution is:

$n=n_{0} \frac{-1+\left[1+4 \frac{n_{b}}{n_{0}}\left[\frac{n_{b}}{n_{0}}-1\right]\left[1-\exp \left(-\Gamma\left(y-y_{b}\right)\right)\right]\right]^{1 / 2}}{2\left[\frac{n_{b}}{n_{0}}-1\right]\left[1-\exp \left(-\Gamma\left(y-y_{b}\right)\right)\right]}$

$\Sigma=\frac{I}{q \mu n \ell}$

where $I=\left(q^{2} \mu \mathrm{n} \ell\right) /(\boldsymbol{E} I)$. The carrier concentration (7) tends asymptotically to $\mathrm{n}$ at a rate which depends on $r$ and, therefore, on the current level $I$. According to this analysis the tail of the accumulated layer can extend inside the epitaxy and it could even reach significant depths.

c) DRIFT REGION. Once the current flow leaves the JFET region, it spreads inside the epilayer with a 450 angle /2/ forming a trapezoidal zone followed by a rectangular zone if the epitaxy is thick enough. Solutions for this region are obtained similarly to the former case but considering a cross section $\mathrm{A}(\mathrm{y})$ linearly depending on the $\mathrm{y}$ coordinate in the trapezoidal 
zone.

The above formulation is valid for electric fields below the saturation value, Esat. For higher fields we have supposed a carrier mobility $\mu(\vec{s})=v_{\text {sat }} / E$ according to $/ 7 /$. The solutions of the general equations (1) and (2) under this condition in the different regions, with its respective approximations, are straightforward calculated.

Finally, the voltage drop across any region and its resistance are analytically obtained integrating the electric field distributions.

\section{$3-\underline{\text { RESULTS }}$}

Electric field distributions obtained from the proposed model and from $2 D$ simulations are plotted on fig. 2, for $V_{D}=5$ and $20 \mathrm{~V}$, the last value corresponding to the $q-\mathrm{s}$ mode. Note that the peak electric field moves inside the epitaxy as the drain voltage increases, showing the JFET lenght modulation effect predicted by the model. A good agreement between theory and 2D simulations is achieved not only inside the epitaxy but at the accumulated surface as shown in the insert.

Normalized carrier concentration is plotted on fig. 3. Let us remark that the tail of the accumulated layer extends up to the body depth even though the device is not in the q-s region. Similarly to the field distribution, the formulation fits the $2 \mathrm{D}$ simulations all through the epilayer.

The I-V characteristics of the fabricated devices are shown in fig. 4, where the gate voltage has been choosen high enough to reach the q-s region. Ixperimental as well as $2 D$ simulations points are in good agreement with the model. On the same figure, the theoretical results without considering carrier velocity saturation are plotted. Note that this effect is just responsible for the current limitation when the transistor is under q-s conditions. The proposed model has been successfully checked as well for the VDMOS devices referred in /3,5/.

\section{$4-$ CONCLUSIONS}

An analytical model for VDMOS devices has been presented. It is based on the solution of the general semiconductor equations with suitable approximations for the different regions into which the epitaxial layer has been divided. This model accounts for the electric field and for the majority carrier concentration distributions which have been checked using BAMBI. This formulation also explains the quasi-saturation effect considering the carrier velocity saturation at high electric fields. Interdigitated VDMOS devices have been fabricated and their output characteristics are in good agreement with the proposed model as well as with the $2 D$ simulations performed.

\section{RETERENCES}

/1/.- B.J. Baliga. IEEE Trans, Electron. Dev., ED-33, 1936 (1986).

12/.- C. Hu, M. Chi and V.M. Patel. IEEE Trans. Electron. Dev., ED-31, 1693 (1984).

/3/.- J.L. Sanchez, M. Gharbi, H. Tranduc and P. Rossel. IEE Proc., 132, 42 (1985).

/4/.- J. Rebollo, J. Millán and F. Serra-Mestres. Proc. of the Symposium on High Voltage and Smart Power Devices. (The Electrochemical Society), 87-1, abs. 92, 130, Philadelphia (USA) (1987).

/5/.- M.N. Darwish. IEEE Trans. Electron. Dev., ED-33, 1710 (1986).

/6/.- A.F. Franz and G.A. Franz. IEEE Trans., CAD-4, 177 (1985).

/7/.- D.M. Caughey and R.E. Thomas. Proc. IEEE Let., 55, 2192 (1967). 


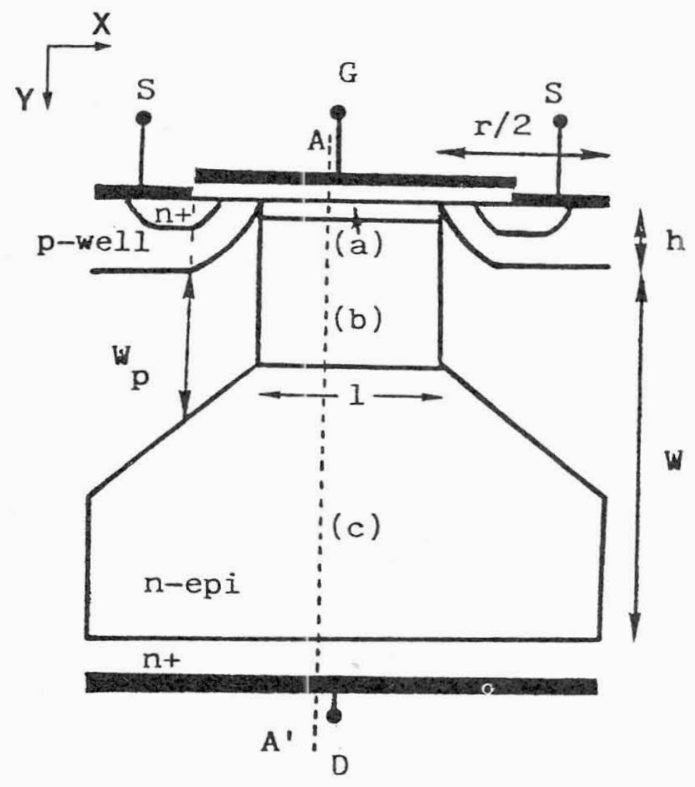

Fig. 1.- VOMOS cross-section. Fabricated structure parameters: $W=40 \mathrm{~mm}, h=5 \mathrm{wm}$, channel length $=2$ um and channel width $=25 \mathrm{~cm}$. $r=60 \mu \mathrm{m}, 1=10 \mathrm{\mu m}, n_{0}=2 \times 10^{14} \mathrm{~cm}^{-3}$,

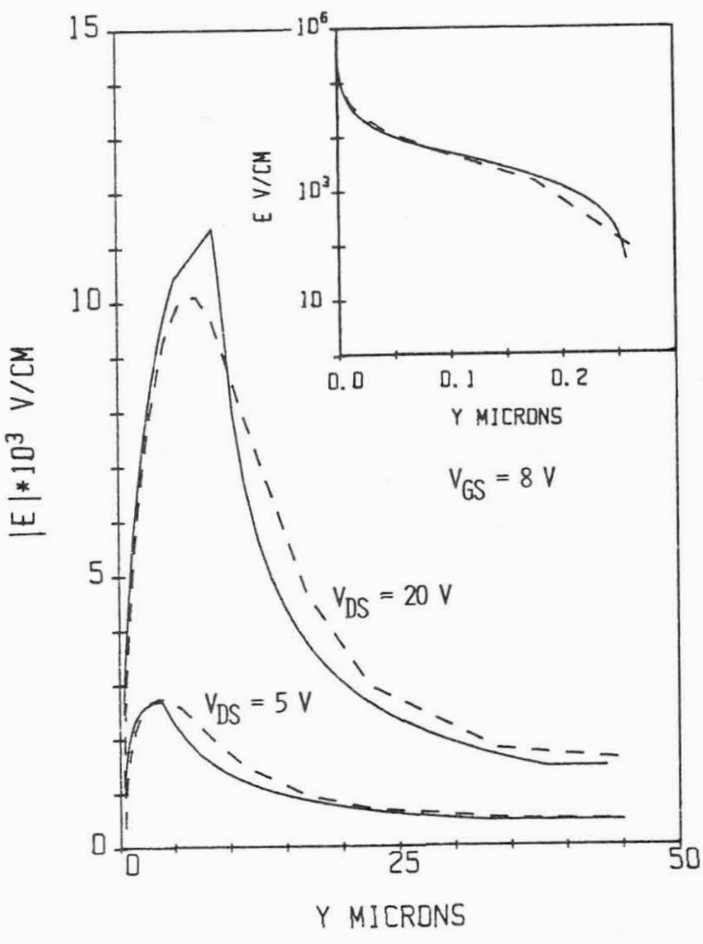

Fig 2.- Electric field along the $A A^{\prime}$ line

- proposed model

- -- 20 simulation

Insert: Electric field in the accumulated layer.

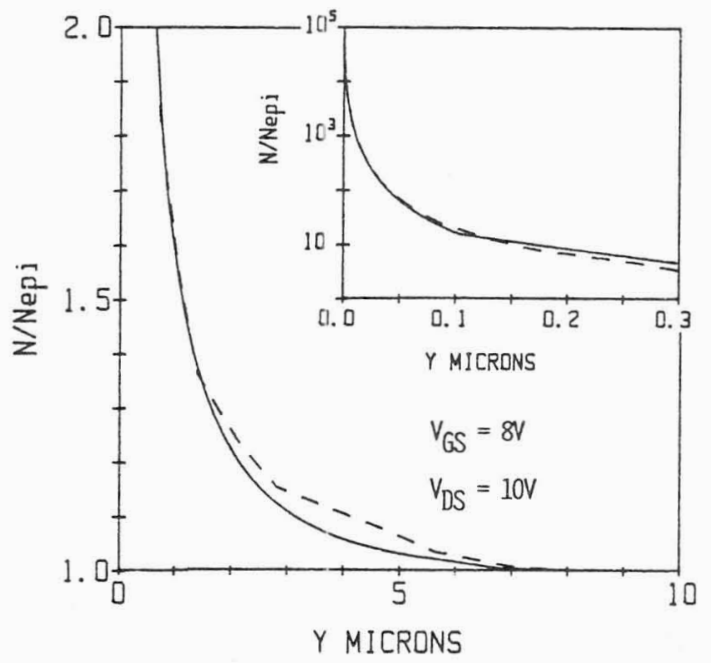

Fig 3.- Normalized carrier concentration along the $A A^{\prime}$ line before $q-s$.

- proposed mode 1

-..-- 20 simulation

insert: Carrier concentration in the accumulated 7 ayer.

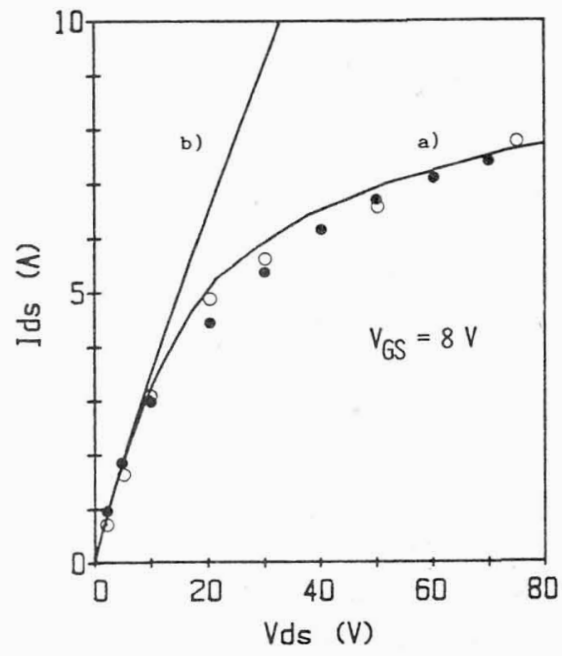

Fig 4. - I-V characteristics model a) with / b) without carrier velocity saturation

- 20 simulation

- experimental points 